\title{
Stress Fracture in Parachute Regiment Recruits
}

Capt R M F Gill

MB, BS, RAMC

Depot The Parachute Regiment \& Airborne Forces*

\section{Lt Col G O Hopkins}

MB, BS, MRCP, DPhys, Med, RAMC

Consultant in Rheumatology \& Rehabilitation

Cambridge Military Hospital, Aldershot, Hants

SUMMARY: A survey of stress fractures occurring in recruits at the Depot of The Parachute Regiment was carried out $\stackrel{\mathbb{D}}{\Omega}$ over a one year period from July 1985 to August 1986. A total of 44 fractures in 36 soldiers were diagnosed. The incidence $\stackrel{\curvearrowright}{\infty}$ was thus $\mathbf{4 . 8 4} \%$, much lower than that found in a recent prospective Israeli study.

Only one case of progression to complete fracture was observed during the study. In contrast to the previous experience with British recruits, the commonest site of stress fracture was the tibial midshaft.

\section{Introduction}

Recruits for The Parachute Regiment undergo particularly arduous training lasting 22 weeks, or longer if injury or poor performance necessitates backsquadding. As a consequence they have a high incidence of lower limb injuries. The relationship of stress fractures to military training has been well documented ${ }^{1-}$ ${ }^{3}$, and the suggestion that prevention may be possible by adjustment of physical training programmes ${ }^{3}$, together with the unsupported hypothesis that the introduction of the Boot Combat High was the cause of greater numbers of lower leg injuries, prompted a survey of a well described condition.

\section{Method}

Seven hundred and sixty five soldiers undergoing basic training at the Depot of The Parachute Regiment between 31 July 1985 and 1 August 1986 were studied. These included adult recruits (613), those joining from Junior Parachute Company (123) and Infantry Junior Leaders Battalion (20), and transfers from other arms (9).

Soldiers presenting with localised lower limb pain and bony tenderness of increasing severity with continued exercise were investigated by ultrasound stress test ${ }^{4}$, and plain X-ray. Those patients with negative $\mathrm{X}$-ray findings but persistent clinical indications underwent bone scintigraphy. The diagnosis of stress fracture was made when one or more of these findings proved positive.

Because of the difficulty of enforcing proper rest of injured recruits at a training establishment, all stress fractures below the knee (except bilateral injuries) were immobilised in a below-knee non-weight-bearing plaster cast for six weeks, and subsequently rehabilitated in the physiotherapy department of the Cambridge Military Hospital before returning to training when pain-free.

\section{Results}

A total of 44 fractures were seen in 36 patients. Three were bilateral ( 2 tibial, 1 calcaneal), 3 had two successive fractures ( 2 of different tibiae, one tibial and metatarsal), and one had two separate fractures at the same time (of 2 ipsilateral metatarsals). The sites of the fractures and the methods used in diagnosis are show in Table 1. The overall incidence of patients with stresso fractures as a percentage of the training population was $4.84 \%$. A total of $71 \%$ of fractures occurred in the tibi $\subseteq$ and $19 \%$ in metatarsals. Other sites accounted for onl 1 $10 \%$ of the total. Out of 44 presentations $30(68 \%)$ wero $\overrightarrow{0}$ diagnosed on X-ray and scan results.

The time of onset of fractures in relation to training shown in Figure 1. In $59 \%$ of cases the fractures occurred between weeks 4 and 9 . Of those presentirf after week 12 of training, all except 2 were in ex-junior soldiers (with up to 6 months previous service).

Three months after concluding the study, 8 patients (22\%) had completed training, $5(14 \%)$ had been medically downgraded, and the remainder were still in training (54\%).

\section{Discussion}

Stress fractures are defects in bone structure, related to repeated stress or strain, which may progress to complete fracture if the precipitating stress is maintained. They are described as occurring in normal bones of healthy individuals doing "everyday activities" without injury". "Everyday activities" being defined as those required to lead a normal life, and therefore cover a vast range of possibilities depending on occupation and lifestyle. It is the absence of a single precipitating incident that particularly characterises the condition.

The aetiology of stress fractures is considered to be $\frac{7}{0}$ associated with the muscular force exerted on bones, as 
Table 1

Site of stress fractures and methods of diagnosis

\begin{tabular}{lccccc}
\hline Site of Injury & No. & Percentage & Ultrasound & X-ray & Bone Scan \\
\hline Neck of femur & 1 & $2 \%$ & ND $^{*}$ & 1 & 1 \\
Shaft of femur & 1 & $2 \%$ & ND $^{*}$ & 1 & ND $^{*}$ \\
Upper third tibia & 5 & $11 \%$ & 5 & 4 & 1 \\
Midshaft tibia & 17 & $39 \%$ & 15 & 10 & 6 \\
Lower third tibia & 9 & $21 \%$ & 1 & 6 & 2 \\
Fibula & 1 & $2 \%$ & 0 & 0 & ND $^{*}$ \\
Os Calcis & 2 & $5 \%$ & 3 & 3 & 2 \\
Second Metatarsal & 3 & $11 \%$ & 5 & 30 & ND $^{*}$ \\
Third Metatarsal & 5 & $100 \%$ & 37 & ND $^{*}$ \\
\hline TOTAL & 44 & & & 12 \\
\hline
\end{tabular}

${ }^{*} \mathrm{ND}$ - procedure not performed.

opposed to the repeated direct trauma of running on hard ground. It has been postulated that the contraction of muscles associated with absorbing the shock of footfall may cause stress fracture ${ }^{7}$.

Certain fracture sites are associated with particular activities - the upper third tibia with athletics, the tibial midshaft with distance running and ballet dancing ${ }^{7,8}$, the femoral neck with military recruit training and running 7,8 , the fibula with skating, jumping and athletics $5,7,9$, the metatarsals with marching ${ }^{7,8}$, and the os calcis with marching and "digging in the heel",

In this study the largest proportion of stress fractures occurred in the tibia $(71 \%)$, a site of fracture associated with running; the next most common site was the metatarsal bones $(18 \%)$, the classical march fracture being well represented. A major prospective study of Israeli recruits by Milgrom et al ${ }^{1}$ also showed the tibia as the site of most fractures $(51 \%)$ with the femur second $(30 \%)$. Our survey showed few femoral fractures,

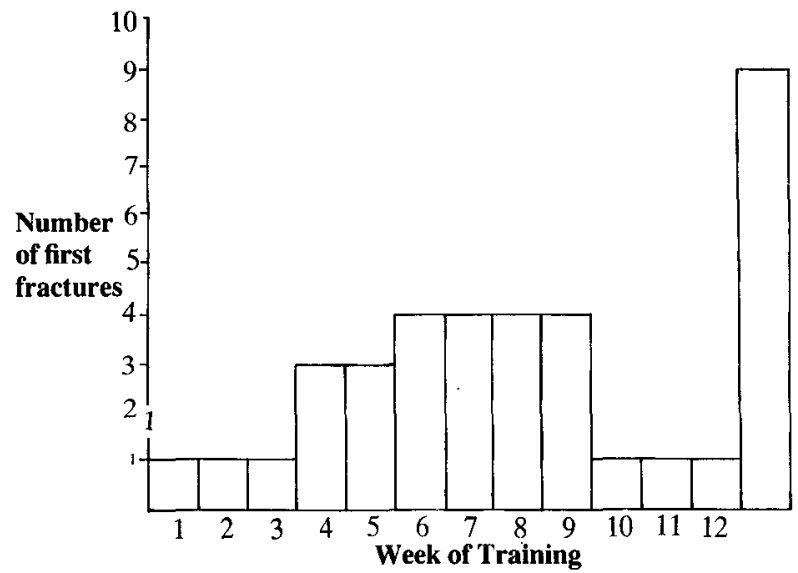

Fig. 1 The time of onset of fractures in relation to training. possibly because they appear to be more commonly asymptomatic than those other sites ${ }^{1}$. The os calcis fracture, which features prominently in US Marine recruit studies ${ }^{2,3}$, is only represented by one case of bilateral fractures in our survey; this finding could be related to a difference in styles of marching.

The observed onset of symptoms in weeks 4 to corresponded with that recorded in a study by Giladi whereas other studies and reports ${ }^{1-3,6}$ have shown onse. particularly in weeks 2 and 3 of training. This may be specifically related to the Parachute Regiment physical training programme which introduces boots onlo gradually. They are worn for drill from week 1 , fo marching (with weight) from week 3 , and for a increasing number of runs from week 4.

Civilian pattern "High-Tech" training shoes are worn for all runs until week 4 , and to a diminishing extent subsequently. The regime of training shoe running was introduced in 1985 as a result of internal study into and discussion of the causes of lower limb injury. Training becomes increasingly arduous up to week 12 when preparachute selection ( $P$ Company) is attempted. The most marked increase in intensity of training occurs at week 6 , and this parallels the increase in incidence of stress fractures.

The suggestion has been made that the Boot Combat High, introduced in 1985, may be responsible for some stress fractures. It has been pointed out ${ }^{11}$ that the boot has no hinge at the ankle, which is therefore partially splinted, preventing normal walking and running motion. This places unusual forces on lower limb bones and is potentially the cause of stress fractures ${ }^{6.8 .11}$. Interestingly, ballet dancers also place unusual stresses on their legs as a consequence of an unconventional form of locomotion; their classical site for stress fracture is the tibial midshaft, which was the most commonly affected site in our survey. 
Soldiers who presented with positive symptoms were diagnosed as having stress fractures if radiography, scintigraphy, or ultrasound stress testing were positive. Milgrom et al $^{1}$ made their diagnosis on similar but slightly more particular criteria, but found much higher incidences of fractures ( $31 \%$ as opposed to $4.84 \%)$. It could be suggested that this resulted from a more aggressive policy of detection. Had the same incidence been observed in our study, a total of about 235 stress fractures could have been expected but only 44 were diagnosed, leaving up to 200 possibly undetected. Although some might have obtained relief in the form of rest or treatment for a concurrent illness, the majority would have continued training and as a consequence, a considerable number of complete fractures should have occurred. In fact, during the period of the study, there was only one case, a recruit who suffered a displaced fracture of the femoral shaft whilst running, and subsequently admitted mild symptoms of pain over the preceding weeks.

The corollary of this is that there would appear to be little justification for extensively investigating minimal symptoms in those recruits who are able to continue training. An exception to this generalisation should, perhaps, be made when symptoms suggest a stress fracture of the femoral neck, as progression to a displaced fracture would be catastrophic for the individual. This reasoning would suggest a policy of progressive investigation. Recruits with persistent symptoms should undergo an ultrasound stress test, and if this is positive, they should be withdrawn from training until they are pain-free. If the test is negative, training could continue but repeat ultrasound should be performed if symptoms are unremitting, and radiographs should be taken if clinical suspicion of stress fracture is high. Negative radiography in these cases should be followed by scintigraphy, and if this failed to demonstrate a fracture, the recruit would be returned to training but kept under medical supervision, bearing in mind the possibility of a negative bone scan in an early stress fracture ${ }^{12}$.

\section{Acknowledgement}

The assistance of all those who helped in the preparation of the paper is gratefully acknowledged. Thanks are also due to Mrs A Davison for typing the manuscript.

\section{REFERENCES}

1. Milgrom $C$, et al. Stress fractures in military recruits. $J$ Bone Joint Surg 1985; 67: 732-735.

2. GILBERT R S and JOHNSON M A. Stress fractures in military recruits - a review of twelve years experience. Milit Med 1966; 131: 716-721

3. GREANEY R B, et al. Distribution and natural history of stress fractures in US Marine Recruits. Radiology 1983; 146: $339-346$

4. Moss A and Mowat A G. Ultrasonic assessment of stress fractures. Br Med J 1983; 286: 1479-1480

5. GILADI M, et al. Unusual distribution and onset of stress fractures in soldiers. Clin Orthop 1985; 192: 142-6

6. Scully T J and Besterman G. Stress fracture preventable training injury. Milit Med 1982; 147: 285-28 कृ 용

7. Devas M. Stress fractures. Edinburgh: Churchi[̈ Livingstone, 1975

8. NIX R A. Stress fractures in the lower extremity. Arkansas Med Soc 1983; 80: 10-13

9. JACKSON BURROWS H. Fatigue fractures of the fibula. Bone Joint Surg 1948; 30: 266-279

10. SChmidt Brudvig T J, et al. Stress fractures in 29 trainees: a one year study of incidence as related to age sex and race. Milit Med 1983; 148: 666-667

11. LiLlYWHITE L P. Personal communication

12. Milgrom C, et al. Negative bone scans in impending tibia stress fractures. Am J Sports Med 1984; 12: $488-491$ 